\title{
Aytekin Ulutaş
}

Balıkesir University, aulutas@balikesir.edu.tr, Balıkesir-Turkey Hüseyin Turhan

Fırat University, hturhan@firat.edu.tr, Elazı̆̆-Turkey

\section{TOZ METALURJİİ İLE ÜRETİLEN Cu-FeB KOMPOZİT MALZEMELERIN MİKROYAPI VE ELEKTRİKSEL ÖZELLIKKLERİNIN İNCELENMESİ}

öz

Bu çalışmada Toz Metalurjisi yöntemi ile Bakır Matrisli Kompozit içerisine, Ferrobor partikülleri takviye edilerek hazlrlanan metal matrisli kompozitin, elektrik özellikleri inceleme altına alınmıştır. Bu amaçla Ferrobor takviye partikülü miktarı, yapı içinde ağırlıkça o1-1, 5-2-2, 5-3-3, 5 oranlarında seçilerek hazırlanan numuneler, toz metalürjisi yöntemi ile preslenmişlerdir. Ardından numunelere sinterleme işlemi için 800-850-900 $\mathrm{C}$ slcaklıklar uygulanarak, farklı sinterleme sicaklıklarının kompozit özelliklerine etkisi incelenmistir. Ayrıca MMC numunelerine iletkenlik deneyleri uygulanmıştır. Numunelerin mikroyapı karakterizasyonu ile SEM, EDS analizleri sonucunda, farklı sıcaklıklarda uygulanan sinterleme işlemi ile sinterleme sıcaklığı artışının numunelerin iletkenlik özelliklerini değiştirmediği görülmüştür. Farklı bileşim oranları dikkate alındığında, yapı içerisinde artan takviye partikülü oranına paralel olarak elektrik iletkenliği değerlerinin o2.5 Ferrobor takviye partikülü oranına kadar değişmediği, bu noktadan sonra yapı içerisinde bir miktar direnç artışı gözlendiği kaydedilmiştir.

Anahtar Kelimeler: Toz Metalurjisi, Metal Matrisli Kompozit, Elektriksel Özellikler, Cu, FeB

\section{INVESTIGATION OF MICROSTRUCTURE AND ELECTRICAL CHARACTERISTICS OF Cu-FeB COMPOSITE MATERIALS PRODUCED BY POWDER METALLURGY}

\section{ABSTRACT}

In this study, mechanical properties of ferroboron reinforced copper composite which produced by the powder metallurgy technique were studied. For this purpose, the ferroboron reinforced particles were mixed into copper powders in the rate of $1-1.5-2-2.5-3-3.5 \%$ in weight. Then sintering to the sample with 800-850-900 ${ }^{\circ} \mathrm{C}$ temperatures, it is studied how different temperatures, effect the composites features. In addition, it was applied the conductivity test to the MMC sample. As the result of SEM EDS analysises with microstructure characterization it has been seen that the increase of sintering temperature doesn't change their conductivities. Elektric conductivity volue doesn't change till $\% 2.5$ Ferroboron consolidation particle rate after this point, it has been recorded that some resistance rise is seen in the structure.

Keywords: Powder Metallurgy, Metal Matrix Composite, Electrical Properties, Cu, FeB 


\section{GIRIŞ (INTRODUCTION)}

Kompozit malzemeler, iki ya da daha fazla sayıdaki, aynı veya farklı guruptaki malzemelerin en iyi özelliklerini, yeni ve tek bir malzemede toplamak amacıyla, makro düzeyde birleştirilmesiyle oluşturulan malzemelerdir [1]. Konvansiyonel üretim tekniklerine bir alternatif olarak geliştirilen toz metalürjisi sağlamış olduğu birçok avantajlar bakımından endüstride yaygın kullanım alanına sahiptir [2]. Bugün istenilen özellikleri sağlamada ileri teknoloji malzemelerine duyulan ihtiyaç giderek artmakta ve tek bileşenli malzemeler ileri mühendislik uygulamalarının ihtiyaçlarını karşılamamaktadır. Bu nedenle üstün özelliklere sahip kompozit malzemelere duyulan ihtiyaç günden güne artmaktadır [3]. Bu bakımdan çeşitli parçaların tasarımı, üretimi açısından büyük önem taşımaktadır [4]. Toz metalurjisi küçük, karmaşık ve boyutsal hassasiyeti yüksek parçaların seri imalatına son derece uygundur. Malzeme kaybı az olmakla birlikte belirli derecede gözenek (porozite) ve geçirgenlik elde edilir [5 ve 6], demir ve bakır esaslı malzemeler mukayese edildiğinde Bakır esaslı malzemelerin daha iyi ısıl iletkenlik ve sürtünme direnci gibi özellikleri olduğunu dile getirir. Saf bakır yüksek elektrik ve ısıl iletkenliğe sahip olmasına karşın, çekme, sürünme ve sertlik gibi mekanik özellikleri düşüktür. Bu bakımdan yüksek çekme mukavemetli ve sert bakır esaslı malzeme geliştirilmesi önemlidir. Bakırın mekanik dayanımı matris içerisine homojen olarak dağılmış sert parçacık takviyesi ile veya yaşlandırma ısıl işlemi ile artırılabilir [7]. Bu çalışma ile verilen literatür ışığında Bakır matris içine FeB takviye edilerek tasarlanan kompozit, toz metalurjisi yöntemi ile üretilmiştir. Hazırlanan kompozite ait numunelerin elektriksel özellikleri araştırılmış ve üretilen kompozitin metalurjik karakterizasyonu belirlenmiştir. Literatürde toz metalurjisi alanında bakır esaslı FeB takviyeli bir kompozit üretimine dair herhangi bir bilgiye ulaşılamamıştır. Bu çalışma ile temelde ferrobor takviye patikülünün bakır matrisi içerisinde, sinterleme sıcaklığına bağlı oluşturduğu intermetalik bileşikler ve bu bileşiklere bağlı elektriksel iletkenlik özellikleri değişimi incelenmiştir.

\section{2. ÇALIŞMANIN ÖNEMI (RESEARCH SIGNIFICATION)}

Bakır kompoziti, takviye partikülü oranının artışına bağıı olarak elektriksel iletkenlik özelliklerinde değişken değerler veren bir yapıya sahiptir. Piyasa şartlarında dayanım özellikleri geliştirilmiş bakır esaslı malzemeler bulunmaktadır. Ancak mekanik özelliklerin geliştirilmesi için yapılan çalışmaların birçoğu iletkenlik özelliklerini olumsuz yönde etkilemekte ve iletkenlik değerlerini düşürmektedir. Bu çalışmada takviye partikülü oranı ile mekanik özellikleri geliştirilen malzemenin iletkenlik özellikleri korunmaya çalışılmıştır. Bu nedenle ferrobor takviye partikülü oranına bağlı bakır kompozitinin iletkenlik değerleri değişimi incelenmiştir.

\section{DENEYSEL ÇALIŞMA (EXPERIMENTAL STUDY)}

Yapılan çalışmada ticari saflıktaki bakır tozuna o1-1, 5-2-2, 53-3, 5 oranlarında FeB tozu karıştırılarak, sabit basınç altında preslenmiştir. Toz malzeme olarak ortalama $35 \mu \mathrm{m}$ boyutlarında \%99,9 saflıkta bakır tozu ile Tablo 1'de özellikleri verilen ve ortalama $50 \mu m$ boyutlarında FeB tozları kullanılmıştır. Bu tozlar karıştırma, presleme ve sinterleme işlemlerine tabi tutulmuştur. 
Ulutaş, A. ve Turhan, H. ,

Technological Applied Sciences (NWSATAS), 2A0111, 2017; 12(2): 43-52.

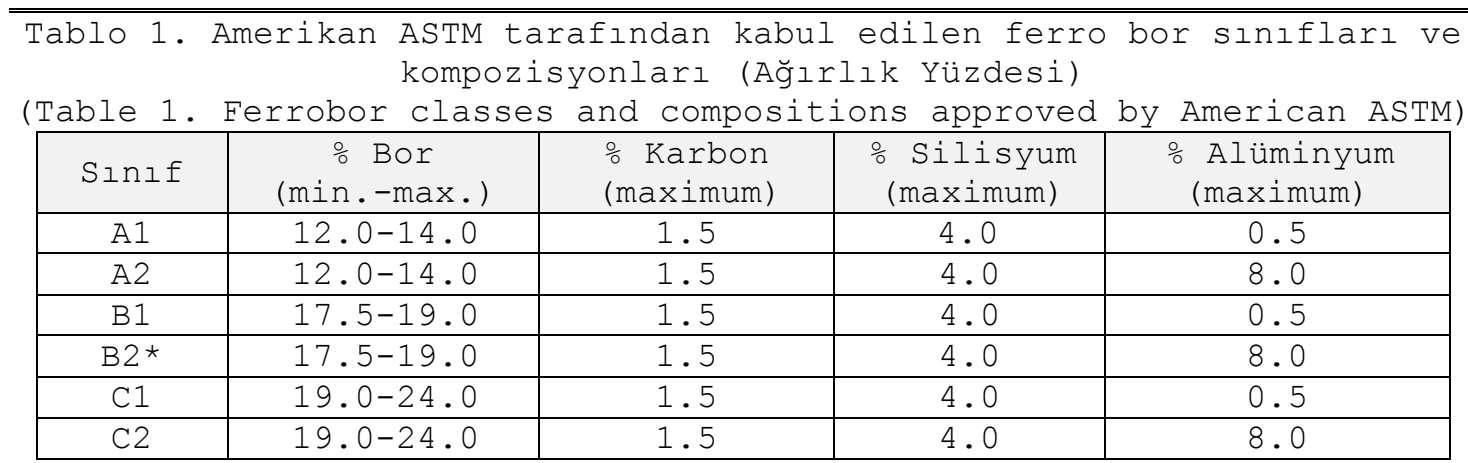

* Çalışmada kullanılan FeB toz sınıfı

Kullanilan tozlar hidrolik preste 600 MPa basınç altında sıkıştırılmıştır. Sinterleme işlemleri, 800-850-900 $\mathrm{C}$ sıcaklıklarda 1 er saat süre ile atmosfer kontrollü tüp fırında gerçekleştirilmiş olup, koruyucu gaz olarak argon kullanılmıştır. Metalografik incelemeler SEM cihazında ve optik mikroskopta yapılmıştır. Presleme sonrası elde edilen numunelerin karı̧̧m konsantrasyonları Tablo 2'de verilmiştir.

Tablo 2. Deneysel çalışmada kullanılan numunelere ait Cu-FeB oranları (Table 2. Cu-FeB ratios of the samples used in the experimental study)

\begin{tabular}{|c|c|c|c|}
\hline $\begin{array}{c}\text { Numune } \\
\text { Numarası }\end{array}$ & Cu oranı (\%) & FeB Oranı ( $\left.{ }^{\circ}\right)$ & $\begin{array}{c}\text { Sinterleme } \\
\text { Sicaklığı }\left({ }^{\circ} \mathrm{C}\right)\end{array}$ \\
\hline C01 & 99 & 1 & 800 \\
\hline C02 & 99 & 1 & 850 \\
\hline C03 & 99 & 1 & 900 \\
\hline C04 & 98.5 & 1.5 & 850 \\
\hline C0 6 & 98.5 & 1.5 & 900 \\
\hline C07 & 98.5 & 1.5 & 800 \\
\hline C08 & 98 & 2 & 850 \\
\hline C09 & 98 & 2 & 900 \\
\hline C10 & 98 & 2 & 800 \\
\hline C11 12 & 97.5 & 2.5 & 950 \\
\hline C13 & 97.5 & 2.5 & 800 \\
\hline C14 & 97.5 & 2.5 & 850 \\
\hline C15 & 97 & 3 & 900 \\
\hline C16 & 97 & 3 & 800 \\
\hline C17 & 97 & 3 & 850 \\
\hline C18 & 96.5 & 3.5 & 900 \\
\hline C20 & 96.5 & 3.5 & 800 \\
\hline C21 & 96.5 & 3.5 & 850 \\
\hline & 100 & 0 & 900 \\
\hline
\end{tabular}

Elektrik iletkenliği testleri için numunelere oda sıcaklığında farklı gerilim değerleri uygulanarak ortaya çıkan voltaj ve direnç değerleri elde edilmiştir.

\section{DENEY SONUÇLARI (EXPERIMENTAL RESULTS)}

\subsection{Mikroyapı Özellikleri (Microstructure Properties)}

Şekil 1-a'da verilen mikroyap resimlerinden $800^{\circ} \mathrm{C}^{\prime}$ de sinterlenen numunelerin gözeneklik dağılımının düzenli olduğu ve takviye partikülü çevresinde biraz daha geniş bir dağılım gösterdiği, $850^{\circ} \mathrm{C}^{\prime} \mathrm{de}$ sinterlenen numuneler söz konusu olduğunda sinterleme sıcaklığının 
Ulutaş, A. ve Turhan, H.,

Technological Applied Sciences (NWSATAS), 2A0111, 2017; 12(2): 43-52.

artışına bağlı olarak gözeneklerin birleşerek ayrıca küreselleşme eğilimi gösterdiği anlaşılmaktadır. Sinterleme sıcaklığının 900C olarak seçildiği numuneler incelendiğinde, yüksek ısı girdisinin daha net sonuçlar doğurduğu görülmektedir. Mikroyapı fotoğrafları incelendiğinde porozitelerde birleşme ve küreselleşme eğilimi açıkça gözlemlenirken bunun yanında takviye partikülü çevresindeki porozite miktarının da azaldığı gözlenmektedir. Artan sinterleme sıcaklığına bağlı olarak poroziteler küreselleşerek birleşme eğilimi göstermektedirler. Aynı zamanda porozite ebatları küçülmekte böylece malzeme içerisinde yoğunluk artışına sebep olmaktadır.
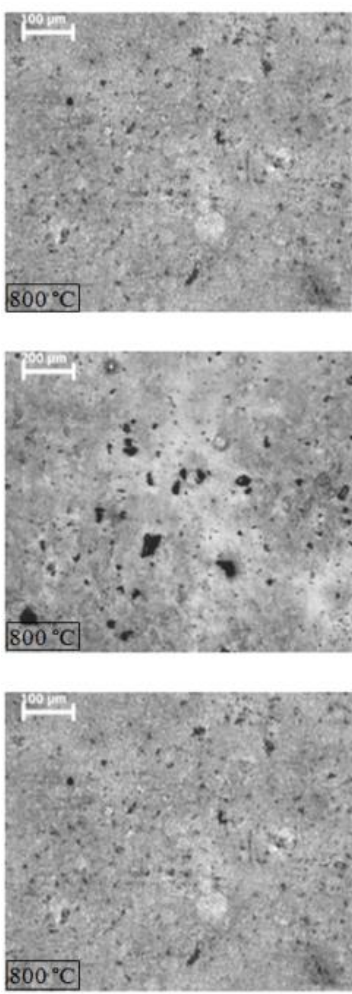

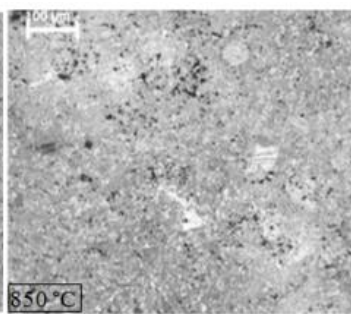

a)
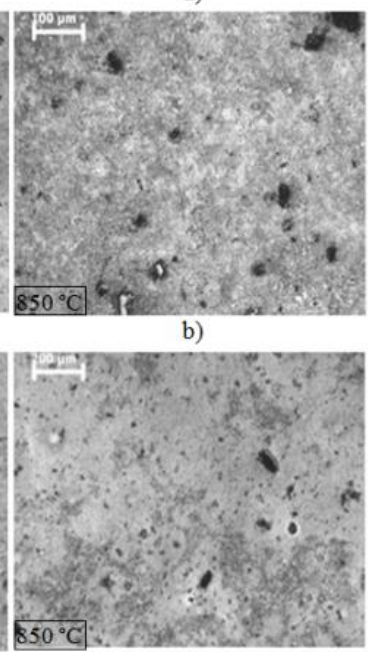

c)
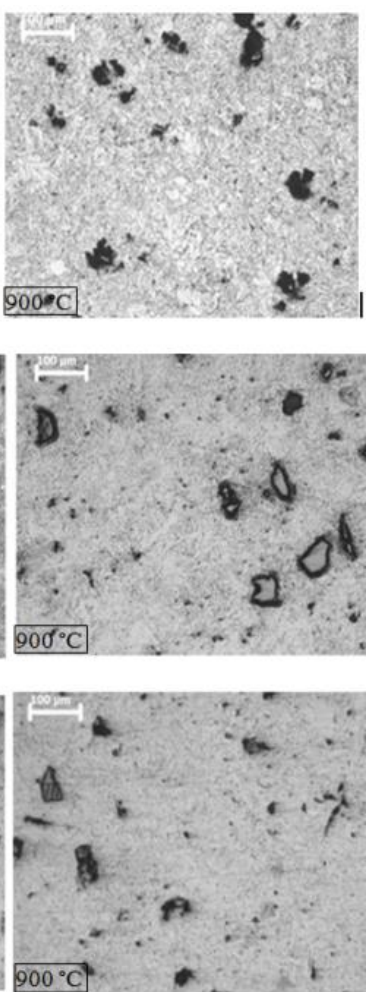

Şekil 1. Sinterleme sıcaklığına bă̆lı mikroyapı değişmleri

a) $\frac{\circ}{\mathrm{F}} \mathrm{FB}$ Takviyeli $800-850-900^{\circ} \mathrm{C}^{\prime}$ de sinterlenmis numuneler

b) $\frac{\circ}{2} \mathrm{FeB}$ takviyeli $800-850-900^{\circ} \mathrm{C}$ 'de sinterlenmiş numuneler

c) $\circ 3 \mathrm{FeB}$ takviyeli $800-850-900^{\circ} \mathrm{C}$ sinterleme sıcaklığına sahip numuneler

(Figure 1. Microstructure changes due to sintering temperature)

( (a) $\% 1$ FeB reinforced samples sintered at 800-850-900 $\mathrm{C}$ )

( (b) $\% 2$ FeB reinforced samples sintered at $800-850-900^{\circ} \mathrm{C}$ )

( (c) $\circ 3$ FeB reinforced samples which have $800-850-900^{\circ} \mathrm{C}$ sintering temperature) 
Ulutaş, A. ve Turhan, H.
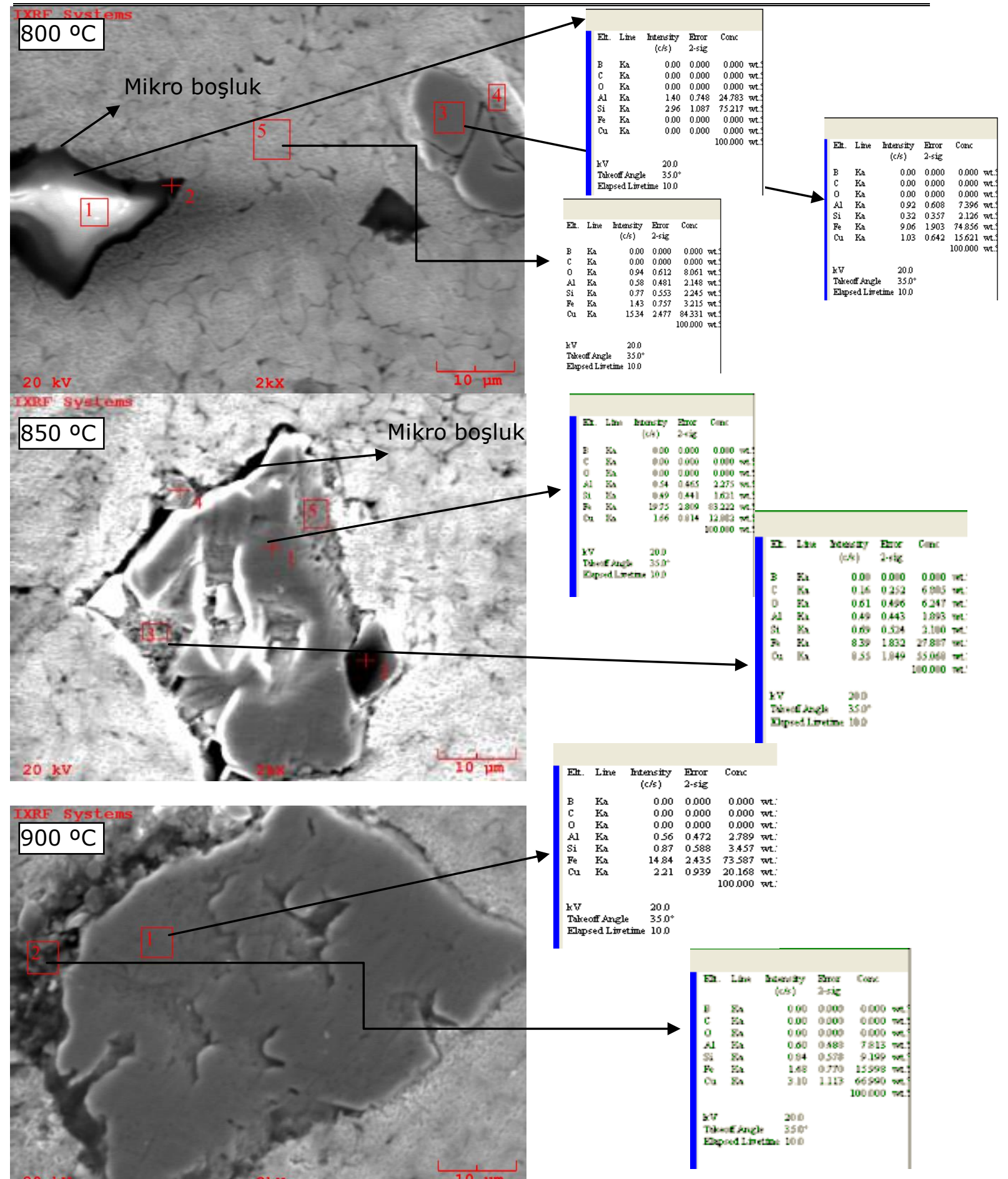

Şekil 2. ㅇ․ㄹ FeB takviyeli 800-850-900 ${ }^{\circ} \mathrm{C}^{\prime}$ de sinterlenen numuneye ait SEM görüntüleri ve EDS analizleri

(Figure 2. SEM images and EDS analyzes of the $\frac{2}{2} .5$ FeB reinforced sample sintered at $800-850-900^{\circ} \mathrm{C}$ )

Şekil 2'te faklı sıcaklıklarda sinterlenmiş o2.5 oranında FeB takviye edilmiş $\mathrm{Cu}$ numunelerin SEM ve EDS analiz sonuçları verilmiştir. $800^{\circ} \mathrm{C}$ sıcaklıkta yapılan sinterleme işleminde matris ile partikül ara yüzeylerinde mikro boşlukların oluştuğu görülmüştür. $850^{\circ} \mathrm{C}$ sıcaklıkta yapılan sinterleme işleminde ise matris ile partikül 
ara yüzeylerinde oluşan mikro boşlukların azaldığı ve bazı partikül ile matris arasında birleşmelerin olduğu tespit edilmiştir. Sinterleme sıcaklığının $900^{\circ} \mathrm{C}$ 'ta çıkarılması, partikül ile matris ara yüzeyinde oluşan mikro boşlukların daha da azalmasına ve partikül/matris ara yüzey geçişlerinin artmasına neden olmuştur.
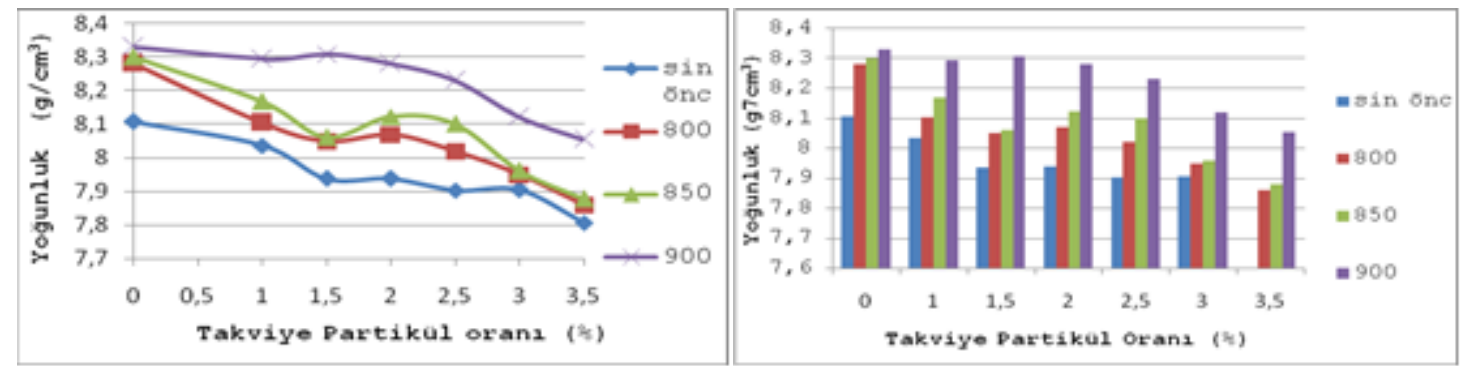

Şekil 3. Partikül oranına bağlı yoğunluk değişim grafiği

(Figure 3. Graphic of density change depending on particule rate)

Şekil 3'de FeB oranının ve sıcaklığın yoğunluk değerlerine etkilerini gösteren grafik verilmiştir. Grafiklerden artan FeB oranının yoğunluk değerlerini azalttığı anlaşılmaktadır. Artan sinterleme sıcaklığı ise yoğunluk değerlerini arttırıcı rol oynamıştır. Bununla birlikte, artan sinterleme sıcaklığı FeB oranının artışına bağlı olarak azalan yoğunluk değerlerininde artmasına neden olmuştur. Zira $800^{\circ} \mathrm{C}$ sinterleme sıcaklığında FeB ilave edilmeyen numunelerin yoğunluk değerleri ile $\% 3.5$ FeB ilave edilen numunelerin yoğunluk değerleri arasında o5.4 fark oluşmuşken $900^{\circ} \mathrm{C}$ sıcaklıkta bu fark \%3.6 olmuştur. Artan sıcaklık, atomların aktivasyon enerjilerini arttıracă̆ından atomların komşu atomlardan koparak yeni alanlara yönelmesi kolaylaşacaktır. Bu nedenle artan sinterleme sıcaklığının Cu partikülleri arasında daha fazla difüzyona sebep olacağı tahmin edilmektedir. Bu durumda gözenekler birleşerek daha düşük enerji seviyesi konumuna geçtikleri sonucu değerlendirilmiştir. Bu durum Xu ve diğ. [8], Rahimian ve diğ [9], Kim [10] tarafından yapılan çalışmalarda da vurgulanmıştır.

\subsection{Elektriksel Özellikler (Electrical Properties)}

Toz metal $\mathrm{Cu}$ malzemelerin FeB takviye partikülü ve sinterleme sıcaklığına bağlı olarak elektrik iletkenliklerinin belirlenmesi amacıyla yapılan bu çalışmada \%1 ile \%3.5 arasında 0.5 artış oranında FeB takviye partikülüne sahip numuneler $800-850-900^{\circ} \mathrm{C}$ sıcaklıklarda sinterlenmiştir. Farklı bileşim oranı ve sinterleme sıcaklığına sahip numunelere 10A'e kadar akım verilmiştir. Numunelerin takviye partikülü ve sinterleme sıcaklığına bağlı gerilimleri ölçülmüş ve takviye partikülü oranı ile sinterleme slcaklığının elektrik iletkenliğine etkisi belirlenmiştir. Bakır malzemelerin en önemli özelliği iletkenliklerinin yüksek olmasıdır. Bu malzemelerin en önemli kullanım alanı da buna paralel olarak iletkenlik istenen yerlerdir. Bakır malzemeler yoğunluk dayanım ilişkisi dikkate alındığında yoğunluklarına göre dayanımlarının düşük olduğu da bilinen bir konudur. Bakır malzemelerin dayanımını artırmak için matris yapıya katılan takviye elemanları genellikle iletkenlik özelliklerini düşürmektedir. Bu çalışmanın en önemli amaçlarından birisi de bakır matris içerisine FeB takviye edilerek hazırlanan, MMC üretim yöntemi ile elde edilen numunelerin elektriksel iletkenlik özelliğini incelemektir. Bu bölümde bakır matris içerisine katılan ilave FeB takviyesinin numunenin iletkenlik özelliklerine etkisi 
Ulutaş, A. ve Turhan, H.,

Technological Applied Sciences (NWSATAS), 2A0111, 2017; 12(2): 43-52.

tartışılacaktır. Bu nedenle aşağıda toz metal numunelere ait akımgerilim ilişkilerini gösteren grafikler verilmiştir.

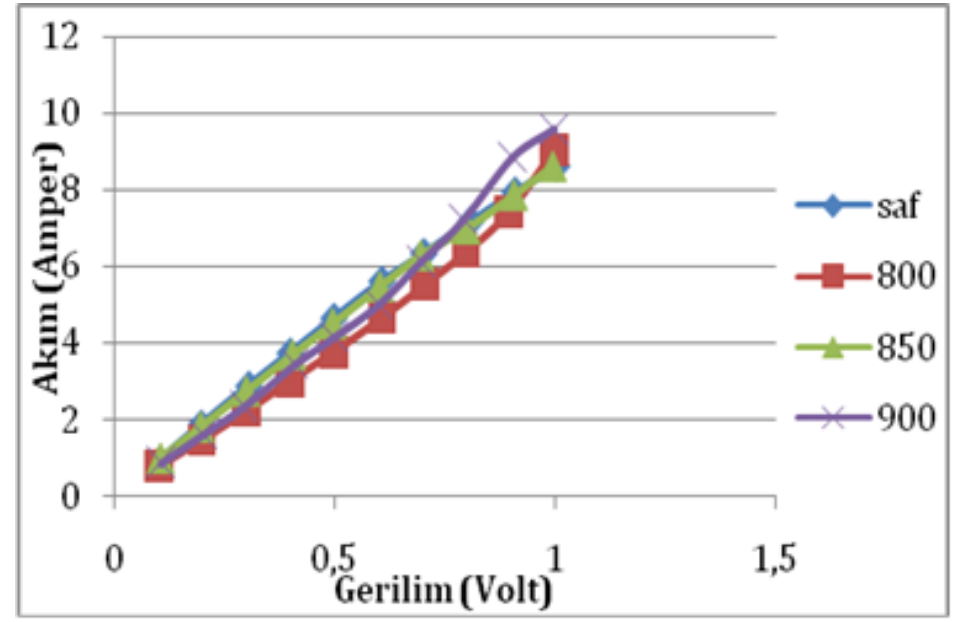

Şekil 4. Sinterleme sıcaklığına bağlı iletkenlik değişimi grafiği

(Figure 4. Graphic of conductivity change depending on sintering temperature)

Sinterleme sıcaklığına bağlı elektrik iletkenliği özellikleri incelendiğinde, aynı bileşim oranına sahip numuneler için sinterleme sıcaklığı etkisinin artan gerilimlerle değiştiği, sonuçta $900^{\circ} \mathrm{C}$ sıcaklıkta sinterlenmiş numune için Şekil 4'de görüleceği üzere, artan gerilim değerleri altında en iyi elektrik iletkenlik değerlerini verdiği görülmektedir. Artan sinterleme sıcaklığının iletkenlik değeri üzerinde daha iyi sonuçlar verdiği (Kurt ve diğ., 2011), (Islak ve diğ., 2014) yapılan çalışmalarda da gözlemlenen bir sonuçtur. Şekil 5 incelendiğinde değişen gerilimler altında farklı sinterleme sıcaklığına sahip numunelerin iletkenlik değerlerindeki değişim görülmektedir. Takviye partikülü oranlarına göre elektirik iletkenlik değerlerindeki değişimler söz konusu olduğunda, Şekil 5 ve Şekil 6, ölçüm değerlerinde artan gerilim ifadesi karşısında ölçülen akım değerlerini vermektedir. Bu noktada $800^{\circ} \mathrm{C}$ ve $900^{\circ} \mathrm{C}$ sicaklıklarda sinterlenen numuneler için net bir fark dile getirmek mümkün değildir. Ancak bileşim oranları dikkate alındığında artan takviye partikülü oranına bağlı olarak iletkenlik değerlerinin bir miktar düştüğü, bu durumun saf bakırın alaşımlandırması durumunda literatürde gözlenen bir durum olduğu görülmüştür [11, 12 ve 13]. Ancak burada dikkat edilmesi gereken husus takviye partikülü artışına bağlı olarak 2 FeB oranına sahip numunenin iletkenlik değerleri olarak en iyi sonuçları verdiği ve takviye partikülü bileşim oranının elektrik iletkenliği değerleri üzerinde önemli değişimler göstermediğidir. 


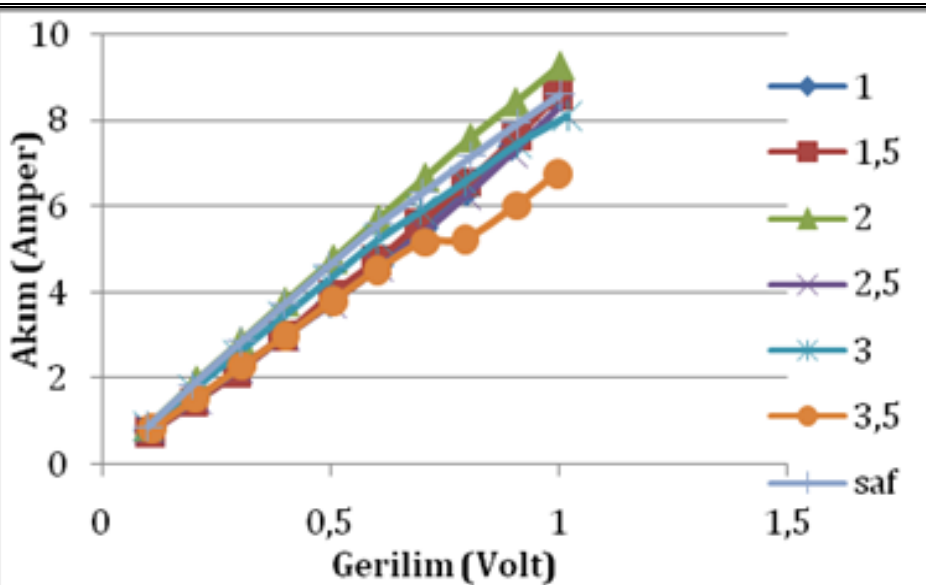

Şekil 5. $800^{\circ} \mathrm{C}$ sıcaklıkta sinterlenen numunelerin takviye partikülü oranına bağlı iletkenlik değişim grafiği

(Figure 5. Conductivity change graphic of the samples sintered at $800^{\circ} \mathrm{C}$ depending on the ratio of the reinforcement particles)

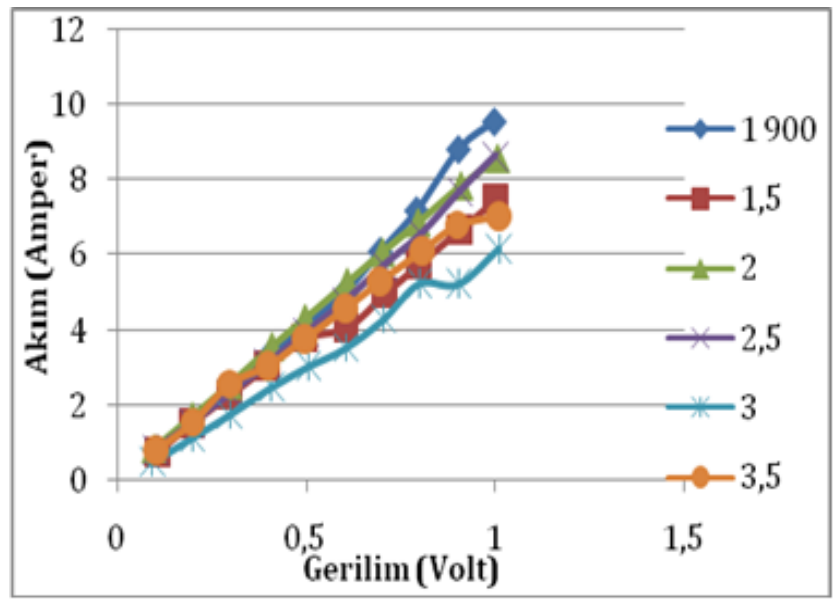

Şekil 6. $900^{\circ} \mathrm{C}$ sıcaklıkta sinterlenen numunelerin takviye partikülü oranına bağlı iletkenlik değişim grafiği

(Figure 6. Conductivity change graphic of the samples sintered at $900^{\circ} \mathrm{C}$ depending on the ratio of the reinforcement particles)

Bilindiği gibi tam yoğun bir katıya bir elektriksel alan uygulanırsa, serbest elektronlar hizlanirlar ve kafes atomlariyla çarpışarak kinetik enerjilerini azaltır veya kaybederler. Meydana gelen akım, uygulanan elektriksel alanın şiddeti ve çarpışma frekansı ile belirlenen ortalama elektron hızı ile orantılıdır. İdeal bir kristalde elektronlar dirençle karşılaşmadan hareket ederler [13]. Fakat gerçek kristallerde elektronlar fononlar, dislokasyonlar, boşluklar yabancı katkı atomları ve herhangi kafes kusurlarıyla çarpışırlar. Bunlarda elektronların hareketini sınırlandırırlar [13, 14 ve 15]. Ayrıca toz metal malzemelerde gerek sinterleme öncesi toz partikül yüzeylerinde oluşan oksitler, gerekse sinterleme sırasında sinter atmosferine bağlı oluşabilecek oksitlerin toz metal numunelerde elektrik iletkenliğini düşürdüğü yapılan çalışmalarda belirtilmiştir [12 ve 13].

\section{GENEL SONUÇLAR (GENERAL CONCLUSIONS)}

Toz metal Cu malzemelerde FeB takviye partikülü miktarının ve sinterleme sıcaklığının elektrik iletkenliğine etkisinin belirlenmesi amacıyla yapılan bu çalışmada aşağıdaki sonuçlar elde edilmiştir. 
- Elektrik iletkenlik durumları incelendiğinde, FeB takviye partikül oranı artışının, numunelerin elektrik iletkenliklerinde o2 ye kadar çok küçük direnç farkları ortaya koyduğu tespit edilmiştir.

- $\quad$ 2 takviye partikülü içeren numunenin elektriksel iletkenlik özelliğinin sabit kaldığı gözlenmiştir. ㅇ.5 FeB takviye partikül oranın üzerinde takviye partikülü artışına bağlı olarak elektriksel iletkenlik kaybının arttığı gözlenmiştir.

- Sabit sinterleme sıcaklığı altında üretilen numunelerde, takviye partikülü artışı elektrik iletkenliğini düşük gerilimlerde az, yüksek gerilimler altında daha çok etkilemiştir. Bu değişimler sinterleme sıcaklığı etkisi altında incelendiğinde, sinterleme sıcaklığı artışının numunelerin elektrik iletkenlik değerlerini kayda değer bir düzeyde etkilemediği, ancak takviye partikülü miktarının artışına bağı sinterleme sıcaklığı artışının, numunelerin iletkenlik değerlerini iyileştirdiği tespit edilmiştir.

Yapılan çalışmalardan elde edilen sonuçlar dikkate alındığında bundan sonraki süreçte bakır esaslı kompozit üzerinde Si ilavesi oransal arttırılarak yarı iletken eşik gerilim değeri üzerinde araştırmalar yapılması önerilir.

\section{KAYNAKLAR (REFERENCES)}

1. Bolay, K.A., (1998). Microstructural Study of Hot Pressed PM Aluminum-Copper and Aluminum Copper Siliconcarbide Composites, M. Sc. Thesis, METU, Ankara.

2. Karagöz, S., Yamanoğlu, R. ve Atabek, S.H, (2009). Sinterlenmiş Toz Metalurjik Bir Çelikte Hata Karakterizasyonu. 5. Uluslararası İleri Teknolojiler Sempozyumu (IATS'09), Karabük, Bildiriler kitabı, ss:957-962.

3. Varol, T., (2012). Aa2024 Matrisli B ${ }_{4}$ Parçaclk Takviyeli Metal Matrisli Kompozitlerin Toz Metalurjisi Yöntemiyle Üretimi ve Özelliklerinin İncelenmesi, Yüksek Lisans Tezi, Karadeniz Teknik Üniversitesi Fen Bilimleri Enstitüsü, Trabzon.

4. Yılmaz, R. ve Özyürek, D., (2009). Toz Metalurjisi ile Üretilen Fe-Cu-C Esaslı Malzemelerin Aşınma Özellikleri, 5. Uluslararası İleri Teknolojiler Sempozyumu (IATS'09), Karabük, Bildiriler kitabı, ss:1230-1235

5. Ekerer, F.A., (2007). Alumina-SiC Parçacık Destekli T/M AlMatriksli Kompozitlerin Üretilmesi Ve Mekanik Özelliklerinin Incelenmesi, Yüksek Lisans Tezi, Sakarya Üniversitesi, Fen Bilimleri Enstitüsü, Sakarya.

6. Xiong, X., Sheng, H.C., Chen, J., and Yao, P.P., (2007). Effects of Sintering Pressure and Temperature on Microstructure Andtribological Characteristic of Cu-Based Aircraft Brake Material, Trans. Nonferrous Met. Soc. of China. Volume:17, pp: 669-675.

7. Tjong, S.C. and Lau, K.C., (2000). Tribological Behaviour of SiC Particle-Reinforced Copper Matrix Composites, Materials Letters, Volume 43, pp:274-280.

8. Xu, X., Lu, P., and German R.M., (2002). Densification and Strength Evoluation in Solid-State Sintering, Journal of Meterials Science, Volume:37, pp:117-126.

9. Rahimian, M., Ehsani, N., Parvin, N., and Baharvandi, H.Z., (2009). The effect of Particle Size, Sintering Temperature and Sintering time on the Properties of $\mathrm{Al}-\mathrm{Al}_{2} \mathrm{O}_{3}$ Composites, made by Powder Metalurgy, Journal of Meterials Processing Teknology, Volume:209, pp:5387-5393. 
10. Kim, T.W., (2008). Determinatin of Densification Behevior of AlSiC Metal Matrix Composite During Consoldation Processes, Meterials Sciences and Engineering, Volume:483, pp:648-651.

11. Özyürek, D., Kibar, E. ve Yılmaz, R., (2009). Toz Metalurjisi ile Üretilen A356 Alüminyum Alaşımının Aşınma Davranışlarının Incelenmesi, 5. Uluslararasi İleri Teknolojiler Sempozyumu (IATS'09), Karabük, Bildiriler Kitabı, ss.963-967.

12. Kurt, A., Ayata, A. ve Issı, F., (2011). Toz Metal Al Malzemelerde Gözeneklilik Oranının Elektrik İletkenliğine Etkisi, 6th International Powder Metallurgy Conference and Exhibition, Ankara, Bildiriler Kitabı, ss:339-344.

13. Islak, S., Kır, D., and Buytoz, S., (2014). Effect of Sintering Temperature on Electrical and Microstructure Properties of Hot Pressed Cu-TiC Composites, Science of Sintering, Volume:46, Issue: 1 , pp:15-21.

14. Buytoz, S., Dağdelen, F., Islak, S., Kök, M., Kır, D., and Ercan, E., (2014). Effect of the TiC Content on Microstructure and Thermal Conductivity of Cu-TiC Composites Prepared by Powder Metallurgy, Journal of Thermal Analysis and Calorimetry (JTAC), Volume.117, Issue:3, pp:1277-1283.

15. Islak, S. and Çelik, H., (2015). Effect of Sintering Temperature and Boron Carbide Content on the Wear Behavior of Hot Pressed Diamond Cutting Segments, Science of Sintering, Volume: 47, pp:131-143. 